\title{
Helicobacter pylori infection among patients with type II diabetes mellitus
}

\begin{abstract}
Introduction: $H$. pylori is the most common human bacterial pathogen that colonizes the gastric epithelium especially in those habitual Qat chewers; it influence can absorption of glucose which is also abnormal in DM patients, its common infection in diabetic patients who have inadequate metabolic control, this study was conducted to reveal the prevalence of $H$. pylori among T2DM and non-DM patients and potential risk factors.
\end{abstract}

Methods: A cross-sectional study was conducted in some hospitals and clinics in Ibb city, Yemen, and there were 200 patients who included in this study. Data were collected through structural intervals questionnaire and sampling information.

Results: The overall prevalence of $H$. pylori among diabetics and non-diabetics was $39.0 \%$. Its prevalence in diabetics was $49 \%$, while in non-diabetics was $29 \%$. There was strong significant association between H.pylori infections and diabetes $\mathrm{P}=0.004$, H.pylori infections and Qat chewing $\mathrm{P}=0.003$ and H.pylori infection and the increase in HbAlc $\mathrm{P}=0.001$

Conclusion: Positive H. pylori DM patients should update their sugar level values and control the disease. Further research is highly recommended on relationship between $H$. pylori infections and diabetes complications (using a cohort study) enhancing personal hygiene and prevention of chewing Qat is essential to decrease the risk of infection.
Volume 7 Issue 2 - 2020

\author{
Enas F Al-Awadhi,' Saleh Bahaj, ${ }^{2}$ Basher Al- \\ Oferi,' Abeer Esmail, ${ }^{3}$ Saad Al-Arnoot' \\ 'Department of Biology, Faculty of Science, Sana'a University, \\ Sana'a, Yemen \\ ${ }^{2}$ Department of Microbiology, Faculty of Medicine, Sana'a \\ University, Yemen \\ ${ }^{3}$ Department of Medical Microbiology, Faculty of Science, lbb \\ University, Yemen
}

\begin{abstract}
Correspondence: Enas F Al-Awadhi, Microbiology Branch, Department of Biology, Faculty of Science, Sana'a University, Sana'a, Yemen, Tel 00967777626667 ,

Email enasfadhl@yahoo.com

Saad Al-Arnoot, Microbiology Branch, Department of Biology, Faculty of Science, Sana'a University, Sana'a, Yemen, Tel 00967774667900,Email saad.alarnoot@gmail.com
\end{abstract}

Received: February 22, 2020 | Published: June 26, 2020

Keyword: helicobacter pylori, T2DM, qat chewing, Ibb city, Yemen

Abbreviations: TNF, tumor necrotic factor; CI, confidence interval; H. pylori, helicobacter pylori, T2DM, type 2 diabetes mellitus

\section{Introduction}

T2DM formerly known as non-insulin-dependent diabetes mellitus or adult-onset diabetes is a metabolic disorder that is characterized by high levels of blood glucose resulting from insulin resistance and relative insulin deficiency. It is an emerging pandemic and is rapidly becoming a serious threat to public health. ${ }^{1} \mathrm{H}$. pylori is a gram-negative, spiral shaped pathogenic bacterium that specifically colonizes on the gastric epithelium, it is one of the most common human bacterial pathogens and infection causes a wide array of gastric disorders, including simple gastritis, peptic ulcers and gastric malignancies. Gastrointestinal inflammation caused by $H$. pylori can influence the absorption of glucose and lipids, which are also abnormal in DM patients. ${ }^{2,3}$ It is a common infection in diabetic patients who have inadequate metabolic control, individuals are colonized by $H$. pylori infection in the gastric antrum, probably because of chemotactic factors such as tumor necrotic factor (TNF), interleukins-IL-1, IL-2, and IL-8, which are present in gastric epithelium. ${ }^{4,5}$ Beside DM the $H$. pylori is also a well be established cause of dyspepsia, the incidence of H. pylori is increased in DM may be due to delay gastric emptying and antraldy smotility, which are important causes of dyspepsia in diabetes, the role of $H$. pylori infection in diabetic dyspepsia is mainly related to blood glucose concentration, reduce of acid secretion and secrete higher of pro-inflammatory cytokines. ${ }^{5,6}$ Recent evidence has shown that qat chewing does indeed delay gastric emptying of a semisolid meal, probably as a result of the sympathomimetic action of cathinone in qat. Inflammation and activated innate immunity have been implicated in pathogenesis of diabetes through insulin resistance, for example, elevated levels of inflammatory cytokines may lead to phosphorylation of serine residues on the insulin receptor substrate, which prevents its interaction with insulin receptors, inhibiting insulin action or altered glucose metabolism may produce chemical changes in the gastric mucosa that promote H. pylori colonization So, individuals with diabetes are more frequently exposed to pathogens than their healthy counterparts. ${ }^{7-10}$ This study was conducted to reveal the prevalence of $H$. pylori among T2DM and non-DM patients with the association between Qat chewing and potential risk factors.

\section{Subjects and methods}

A cross-sectional study was conducted in T2DM and non-diabetic patients attending during a period between Nov 2016 and ending in Dec 2017, This study recruited 200 diabetics and non-diabetics patients there were age ranged 35 and over years old, criteria were studied. Patients of type-1 diabetes, patients already on steroid or immunosuppressive or $\mathrm{H}$. pylori eradication therapy, non-cooperative patients who refuse to give consent or participate in the study were excluded from the study. Written informed consent was taken and the study was approved by the Ethics Committee. Diabetics and nondiabetics patients were tested for $H$. pylori infection by stool antigen by immunochromatographic kits, fasting blood glucose, and glycated hemoglobin $(\mathrm{HbA} 1 \mathrm{c})$. Data was analyzed with the appropriate statistical methods, Chi-square test. Tests were considered significant if $\mathrm{P}$ values were less than 0.05 , Odds ratio and $95 \%$ confidence interval (CI) were also calculated.

\section{Results}

The study population comprised 200 patients, 100 apparently non- diabetic patients (29 male and 71 females) and 100 T2DM (34 males and 66 females). The mean of their ages were $45.3 \pm 11.1$ and $50.9 \pm 12.8$ respectively, $49(49 \%)$ diabetics were positive for 
H. pylori antigen compared to $29(29 \%)$ non-diabetics, which was found to be significant $\left(\mathrm{X}^{2}=8.4, p=0.004\right.$, OR (95\% CI 2.4(1.3-4.2) Table1. In the present study, the prevalence of $H$. pylori was found to be higher among 35-45years old of diabetics and non-diabetics and don't show significant relations among diabetics and non-diabetics with $H$. pylori $P=0.625, \mathrm{~F}$ test $=0.7$, implying that $H$. pylori is not associated with age. Similarly, the gender distribution was found to be non-statistically significant among diabetics and non-diabetics $P=0.643, \mathrm{x}^{2}=0.24, H$. pylori is not associated with gender Table 2 . It is in contrast to the positive $H$. pylori with smoking, the results show $22.5 \%$ diabetics and $3.5 \%$ non-diabetics were smoked and 77.5
$\%$ diabetics and $96.5 \%$ non-diabetics were non-smoked, there were no associations between smoking and positive $H$. pylori $p=0.529$ and $\mathrm{F}$ test $=0.3$ OR $(95 \% C I) 8.1(0.9-66.5)$. H. pylori positivity was more among diabetic patients with Qat chewing group which was statistically significant $(P=0.003, \mathrm{~F}$ test $8.6, O R(95 \% C I)$ 5.4(1.617.7)). Among diabetics, Qat chewing group had $89.7 \%$, while it was $62.0 \%$ in patients without diabetics Table 3. Mean HbA1c among diabetics with $H$. pylori infection was significantly greater than $H$. pylori negative diabetics $(10.02 \pm 1.5 \%$ and $9.1 \pm 1.2 \%$, respectively, test $=3.3 p=0.0001)$ Table $4 \& 5$.

Table I The association between positive H. pylori with diabetics and non-diabetics groups at hospitals based study, in Ibb city, Yemen $20 \mathrm{I} 7$

\begin{tabular}{|c|c|c|c|c|c|c|}
\hline \multirow[t]{2}{*}{ H. pylori } & \multirow{2}{*}{$\begin{array}{l}\text { Diabetic patients } \\
\text { No (\%) }\end{array}$} & \multirow{2}{*}{$\begin{array}{l}\text { Non-diabetic } \\
\text { patients } \\
\text { No (\%) }\end{array}$} & \multicolumn{2}{|l|}{ Total } & \multirow[t]{2}{*}{ OR (95\%CI) } & \multirow[t]{2}{*}{ P-value } \\
\hline & & & No (\%) & $\mathbf{X}^{2}$ & & \\
\hline Positive & $49(62.8)$ & $29(37.2)$ & $78(39.0)$ & & & \\
\hline Negative & $5 I(4 I .8)$ & 71 (58.2) & $122(6 \mid .0)$ & 8.4 & $2.4(1.3-4.2)$ & 0.004 \\
\hline Total & $100(50)$ & $100(50)$ & $200(100)$ & & & \\
\hline
\end{tabular}

OR (95\% Cl): odd ratio, 95 confidence interval, $\mathrm{p}<0$ significant

Table 2 The association between positive H. pylori and age, gender groups at hospitals based study, 2017

\begin{tabular}{llllll}
\hline Age & Diabetics & Non-diabetics & Total & & p-value \\
& patients & patients & & \\
& $\%$ & $\%$ & $\%$ & F test & \\
\hline $35-45$ & 48.9 & 65.5 & 55.1 & 0.7 & 0.625 \\
$46-55$ & 20.4 & 31 & 24.4 & & \\
$>55$ & 30.6 & 3.4 & 20.5 & & \\
Total & 62.8 & 37.2 & 100 & & \\
Gender & $\%$ & $\%$ & $\%$ & $X^{2}$ & P-value \\
Male & 34.6 & 20.6 & 29.5 & 0.24 & 0.643 \\
Female & 65.3 & 79.3 & 70.5 & & \\
Total & 62.8 & 37.2 & 100 & & \\
\hline
\end{tabular}

$\mathrm{P}<0.05$ significant

Table 3 The association between smoking, Qat chewing and positive H. pylori at hospitals based study, 2017

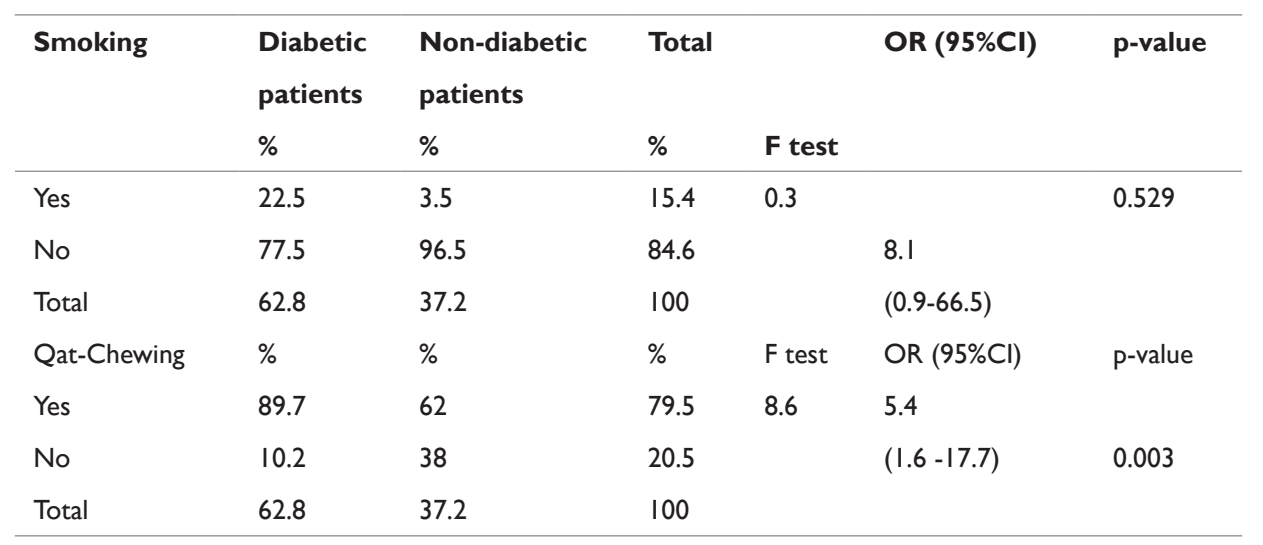

OR $(95 \% \mathrm{Cl})$ : odd ratio, 95 confidence interval, $\mathrm{p}<0.05$ significant 
Table 4 Association between $\mathrm{H}$. pylori with $\mathrm{HbAlc}$ at hospitals based study, 2017

\begin{tabular}{lllll}
\hline HbAlc test & $\begin{array}{l}\text { Diabetes with } \boldsymbol{H} \text {. pylori } \\
\text { Positive }=49\end{array}$ & $\begin{array}{l}\text { Diabetes with } \boldsymbol{H} \text {. pylori } \\
\text { Negative=5 I }\end{array}$ & t test & p value \\
\hline Mean \pm SD & $10.02 \pm 1.5$ & $9.1 \pm I .2$ & 3.3 & $0.00 I$ \\
\hline
\end{tabular}

OR $(95 \% \mathrm{Cl})$ : odd ratio, 95 confidence interval, $\mathrm{p}<0.05$ significant

Table 5 Association between Qat chewing, HbAlc as risk factors for H.pylori among diabetics at hospitals based study, in lbb city, Yemen $20 \mathrm{I} 7$

\begin{tabular}{lll}
\hline Variable & OR(95\% CI $)$ & P value* $^{*}$ \\
\hline Qat chewing & $4.2(1.2-14.2)$ & 0.02 \\
HbAlc & $10.5(3.2-35.3)$ & 0.001 \\
\hline
\end{tabular}

*Logistic regression

\section{Discussion}

This study aims to determine the prevalence of $H$. pylori infections in T2DM and non-diabetic patients, and to identify the association between $H$. pylori infections and diabetes mellitus. The overall prevalence of $H$. pylori among diabetics and non-diabetics was $39.0 \%$. Its prevalence in diabetics was $49 \%$, while in non-diabetics was $29 \%$. From these results we can notice that diabetics have higher infections with $H$. pylori than non-diabetics and this is agreement with $88 \%$ vs. $76 \%,{ }^{11} 70.5$ vs. $29.5,{ }^{12} 64.5 \%$ vs. $43.6 \%,{ }^{13} 60 \%$ vs. $26.6 \%{ }^{14} 59 \%$ vs $31 \%$ and $75 \%$ vs $25 \% .{ }^{15,16}$ Other studies revealed disagreement in the prevalence between $H$. pylori infection in diabetics and non-diabetics $21.3 \%$ vs. $20.2 \%,{ }^{17} 42.9 \%$ vs. $43.1 \%,{ }^{18} 73.5 \%$ vs. $76.5 \% .{ }^{19}$ This study contradicts our results which may be attributed to the inconsistent measurements used for $H$. pylori positivity, IgG antibodies were used to define infection in most studies. IgG antibodies reflect prior infection, but are not sensitive indicators of current infection. The ethnic heterogeneity and may be small sample size made their results insignificant. In the present study, there is a statistically significant association between positive $H$. pylori and diabetes mellitus $p=0.004$, pathogenesis of H. pylori infections in diabetic patients has not been defined clearly. However, this study may contributed to the belief that $H$. pylori infections are more prevalent among people with diabetes, but it is not clear whether diabetics have more susceptibility to this infection or H. pylori infections increases the susceptibility to diabetes. There is no statistically significant association between diabetics and non-diabetics patients and positive $H$. pylori with age $(P=0.625)$, this study is agreement with Saadallah ${ }^{20}$ who found that no statistically association, ${ }^{20}$ and disagreement with Oldenburg who found statistically significant in all age categories. ${ }^{21}$ The reason for this difference, our results are not statistically significant because the age group starts from 35 years while Oldenburg, the age group starts from child to elderly. The reason for this difference is not clear.

Regarding gender, this study reveals no statistically significant association between gender and infection with $H$. pylori for both $P=0.643$. These results are agreement with study conducted in Turkey, ${ }^{13}$ and disagreement with study conducted in Palestine, there was statistically significant $P<0.05 .^{20}$ The present study shows no significant association between education levels and infections of H. pylori for both $p=0.625$. These results are agreement with study conducted in Palestine. ${ }^{20}$ The present study found an insignificant relationship between $H$. pylori infections and smoking $p=0.529$. These findings are agreement with, ${ }^{22}$ who had reported no association between $H$. pylori infections and smoking in Nigeria. This reason may due to our inability to divide the smokers to light smokers, moderate smokers and heavy smokers to find if there is an association between $H$. pylori infections and diabetes mellitus with smoking. In this study there is a statistically significant association between diabetics infected with $H$. pylori and Qat chewing $P=0.003$, this statistical significant is may be due to contamination of Qat. Studies on the effect of Qat and infection with $H$. pylori are scarce despite the increase in the knowledge of Qat pharmacology and chemistry. Thus, the need for a study was determined to be useful to illuminate the association between Qat chewing and infection with H. pylori. There is no previous study that discussed the relationship between $H$. pylori infections among both diabetics and non-diabetics with Qat chewing, but there is a study that revealed a statistically significant association between H. pylori infections and Qat chewing conducted in Sana'a city with $P=0.004 .^{23}$ In this study there is a statistically significant association between $H$. pylori infections and $\mathrm{HbAlc}$ results among diabetics $p=0.001$. These results are agreement with studies conducted in New York and Taiwan. ${ }^{24,25}$ It may be possible that a good glycemic control could hinder H. pylori colonization. Our Limitations in this study, that is, our design was a cross-sectional study instead of a casecontrol study due to the presence of unmatched group (difficult to get matched group), lack of patients. ${ }^{26}$

\section{Conclusion}

Positive H. pylori DM patients should update their sugar level values and control the disease. Further research is highly recommended on relationship between $H$. pylori infections and diabetes complications, (using a cohort study). Qat chewing is highly prevalent in Yemeni people with T2DM. There is an association between qat chewing and the development of $H$. pylori. Qat chewers have a more than three times higher risk of developing H.pylori than those who do not chew qat.

\section{Acknowledgment}

The authors were grateful to the Department of Biology, Faculty of Science, Sana'a University, Sana'a, Yemen for supporting this research. We are also acknowledging the contribution of all patients in science, who support and contribute to this study.

\section{Conflicts of interest}

The authors declare no conflict of interest.

\section{Funding}

None. 


\section{References}

1. He C, Yang Z, Lu N-H. Helicobacter pylori infection and diabetes: is it a myth or fact? World J Gastroenterol. 2014;20(16):4607-4617.

2. Parsonnet J. Helicobacter pylori and gastric cancer. Gastroenterol Clin North Am. 1993;22(1):89-104.

3. Wotherspoon A, Ortiz-Hidalgo C, Falzon M, et al. Helicobacter pyloriassociated gastritis and primary B-cell gastric lymphoma. Lancet. 1991;338(8776):1175-1176.

4. Malaty HM. Epidemiology of helicobacter pylori infection. Best Pract Res Clin Gastroenterol. 2007;21(2):205-214.

5. Olimy MG. Course of helicobacter pylori infection in patients with type 2 diabetes mellitus in comparison with healthy persons. 2013.

6. Bener A, Micallef R, Afifi M, et al. Association between type 2 diabetes mellitus and helicobacter pylori infection. Turk $J$ Gastroenterol. 2007;18(4):225-229.

7. De Luis D, De La Calle H, Roy G, et al. Helicobacter pylori infection and insulin-dependent diabetes mellitus. Diabetes Res Clin Pract. 1998;39(2):143-146.

8. Gentile S, Turco S, Oliviero B, et al. The role of autonomic neuropathy as a risk factor of helicobacter pylori infection in dyspeptic patients with type 2 diabetes mellitus. Diabetes Res Clin Pract. 1998;42(1):41-48.

9. Manco M, Putignani L, Bottazzo GF. Gut microbiota, lipopolysaccharides, and innate immunity in the pathogenesis of obesity and cardiovascular risk. Endocrine reviews. 2010;31(6):817-844.

10. Wellen KE, Hotamisligil GS. Inflammation, stress, and diabetes. J Clin Invest. 2005;115(5):1111-1119.

11. Pareek R, Kannan M. Prevalence of $H$. pylori infection in type 2 diabetes mellitus patients in rural Rajasthan-a case control study. Inter J Med Sci Clin Invent. 2014;1(1):1-14.

12. El-Sakka MA, Jabal EMA, Nasser LM. The role of helicobacter pylori infection, and malnutrition among type 2 diabetic medical services patients in the Gaza Strip. International Journal of Clinical Medicine. 2013;4(12):556-560.

13. Kayar Y, Pamukçu Ö, Eroğlu H, et al. Relationship between helicobacter pylori infections in diabetic patients and inflammations, metabolic syndrome, and complications. Int J Chronic Dis. 2015:290128.

14. Talebi-Taher M, Mashayekhi M, Hashemi MH, et al. Helicobacter pylori in diabetic and non-diabetic patients with dyspepsia. Acta Med Iran. 2012;50(5):315-318.
15. Tawfeeq RD, Amin ZA, Nuraddin SM, et al. Relationship between type II diabetes mellitus and helicobacter pylori infection in Erbil city. Zanco J Med Sci. 2019;23(1):43-50.

16. Wali N, Waheed A, Aslam M. Association of helicobacter pylori infection in patients suffering from type 2 diabetes mellitus. Pakistan $J$ Med Health Sci. 2018;12(2):535-537.

17. Han X, Li Y, Wang J, et al. Helicobacter pylori infection is associated with type 2 diabetes among a middle-and old-age Chinese population. Diabetes Metab Res Rev. 2016;32(1):95-101.

18. Zhou F, Zhong X, Chen J, et al. Helicobacter pylori infection associated with type 2 diabetic nephropathy in patients with dyspeptic symptoms. Diabetes Res Clin Pract. 2015;110(3):328-334.

19. Nam S-J, Park SC, Lee SH, et al. Helicobacter pylori eradication in patients with type 2 diabetes mellitus: multicenter prospective observational study. SAGE Open Med. 2019;7:2050312119832093.

20. Saadallah N. Assessment of helicobacter pylori infection as riskfactor for type 2 diabetes mellitus in Gaza Strip. The Islamic University of Gaza. 2013.

21. Oldenburg B, Diepersloot R, Hoekstra J. High seroprevalence of helicobacter pylori in diabetes mellitus patients. Dig Dis Sci. 1996;41(3):458-461.

22. Oluyemi A, Anomneze E, Smith S, et al. Prevalence of a marker of active helicobacter pylori infection among patients with type 2 diabetes mellitus in Lagos, Nigeria. BMC Res Notes. 2012;5(1):284.

23. Gunaid AA, Hassan NA, Murray-Lyon I. Prevalence and risk factors for Helicobacter pylori infection among Yemeni dyspeptic patients. Saudi Med J. 2003;24(5):512-517.

24. Chen Y, Blaser MJ. Association between gastric helicobacter pylori colonization and glycated hemoglobin levels. J Infect Dis. 2012;205(8):1195-1202.

25. Hsieh MC, Wang SS, Hsieh YT, et al. Helicobacter pylori infection associated with high $\mathrm{HbAlc}$ and type 2 diabetes. Eur J Clin Invest. 2013;43(9):949-956.

26. Hassan NAGM, Gunaid AA, Murray Lyon IM. Khat [Catha Edulis]: Health aspects of qat chewing. East Mediterr Health J. 2007;13(3):706718. 